Revista Eletrônica do Mestrado

Profissional em Administração da UnP

edunp

V. 12, N.2, 2020

ISSN 1984-4204

https://repositorio.unp.br/index.php/raunp

https://doi.org/10.21714/raunp.v12i2.2042

\title{
Internacionalizando doces: o caso de uma empresa do ramo alimentício situada no Vale do Taquari/ RS
}

\section{Internationalizing sweets: the case of a food company located in Vale do Taquari/RS}

\author{
Maicon da Silva ${ }^{\mathrm{a}}$, Luis Carlos Alves da Silva ${ }^{\mathrm{b}}$ \\ a Mestre em Administração. Pós-Graduando em Docência no Ensino Técnico e Profissional, Tutoria em Educação a Distância. \\ Universidade de Santa Cruz do Sul.maicon213@bol.com.br \\ b Mestrando em Administração na área de Gestão Estratégica de Marketing. Universidade de Santa Cruz do Sul.1uiscarlosalves0207@ \\ gmail.com
}

\begin{abstract}
Resumo
O caso de ensino, realizado a partir do estudo da empresa do segmento de candies, atende aos seguintes objetivos educacionais: (a) entender o processo pelo qual uma empresa do segmento de candies se internacionalizou; (b) analisar e avaliar os riscos e dificuldades do processo de internacionalização; (c) analisar e avaliar a escolha entre a expansão no mercado doméstico e aprofundamento da internacionalização; (d) Investimentos em uma nova unidade em outra região visando facilitar a logística de exportação e consequente redução de preços dos produtos vendidos. Também na entrevista com o responsável do setor internacional, onde o mesmo relata que no ano de 1998 aconteceu por acaso uma venda internacional para a Venezuela. O caso pode ser utilizado em cursos de graduação e pós-graduação - stricto e lato sensu. Pode ser utilizado, também, em workshops de discussões sobre as dificuldades e soluções encontradas por empresas brasileiras em seu processo de internacionalização.
\end{abstract}

Palavras-chave: Internacionalização; Investimentos; Empresas Brasileiras.

\begin{abstract}
The teaching case, based on the study of the candies business, meets the following educational objectives: (a) to understand the process by which a company in the candies segment has internationalized; (b) analyze and evaluate the risks and difficulties of the internationalization process; (c) analyze and evaluate the choice between expansion in the domestic market and deepening of internationalization; (d) Investments in a new unit in another region aimed at facilitating export logistics and consequent reduction of prices of products sold. Also, in the interview with the person in charge of the international sector, where the same one reports that in the year 1998 happened by chance an international sale for Venezuela. The case can be used in undergraduate and postgraduate courses - stricto and lato sensu. It can also be used in workshops to discuss the difficulties and solutions encountered by Brazilian companies in their internationalization process.
\end{abstract}

Keywords: Internationalization; Investments; Brazilian Companies. 


\section{Apresentação}

Em meados da década de 30, uma família interiorana trabalhava com seus vizinhos desempenhando atividades agrícolas, sendo esta uma prática rotineira daquela época. Como forma de interação familiar e fonte de renda complementar, a família produzia candies de forma artesanal, em tachos de cobre no fogão a lenha.

Não satisfeito com a situação de sua família, e influenciado por seus avôs, Nestor, mexendo em seu tacho com uma colher de madeira, começa a se encantar pela fabricação de candies. Com apenas 12 anos, num Ford 29, com carroceria de madeira, acompanhava o pai nas entregas dos seus produtos nas casas de comércio ao longo de estradas de chão batido, transformando dificuldades em aprendizado. E assim, com seu jeito afável de ser, Nestor começou a desenhar uma linda história em companhia de sua esposa Isolina, perpassando seus valores para os filhos que viriam a ter.

Anos mais tarde, Nestor e Isolina começam a preparar seus filhos (Alexandre, Fernando e Ricardo), para fazerem a sucessão do seu negócio. A diversidade de aptidões e a personalidade dos mesmos fizeram com que essa pequena empresa alçasse voos mais altos, tornando-os uma das maiores empresas no segmento que atuam no Brasil.

\section{A formação do modelo de negócio}

$\mathrm{Na}$ década de 90, nasceu uma empresa que veio para revolucionar o segmento de candies no Brasil, trazendo um novo conceito para este segmento. Neste mesmo período a União Soviética some do mapa. A moda passa a ser ditada pelos jovens. Começa a era grunge, liderada pela banda americana Nirvana. Ayrton Senna conquista o tricampeonato mundial de Fórmula 1, em Suzuka, no Japão.

Passado esse período, a empresa entendeu que seu negócio inicial precisava ser reestruturado, alterando seu foco inicial, que era de distribuição, passando a fabricação, inicialmente de refrescos em pó. Nesse mesmo ano, entrou em vigor o plano real. Depois de décadas, a inflação voltou a um patamar relativamente baixo e o país começou a crescer de maneira rápida e sustentável.

Por um acaso do destino, em 1998 a empresa havia experimentado uma exportação devido a uma venda de Refresco para a Venezuela. A direção da empresa sempre entendeu ser importante o mercado externo, sendo que a partir deste momento, começaram a trabalhar com exportação. Neste mesmo ano, a crise na Rússia atinge o Brasil. Registra-se fuga maciça de capital: US\$ 15 bilhões em um só dia. No dia 10, a Bovespa cai 15,82\%. O governo reage com cortes nos gastos na área social. Os juros explodem e chegam à taxa de $42,12 \%$. FHC é reeleito em primeiro turno, com 53,06\% dos votos válidos. Lula fica em segundo, com 31,71\%. "Eu sou o melhor candidato de partida, mas o pior na chegada" avalia o petista, após a terceira derrota na disputa para a Presidência. O PT agita-se pensando que em 2002 vai competir com outro nome. O FMI (Fundo Monetário Internacional) aprova empréstimo para que o Brasil não vá para o fundo do poço junto com a Rússia. A ajuda chegará a US\$ 41 bilhões. Em Washington Malan ganha pinta de presidenciável.

Não satisfeita com a situação, e buscando um alinhamento com o mercado consumidor, a empresa alterou o seu nome. A partir desse entendimento, e, devido ao pouco espaço, começou a construção de um novo parque industrial, cerca de 10 vezes maior que o existente passando a ocupar uma área de $40.000 \mathrm{~m}^{2}$. Também, este momento foi caracterizado como a era dos CDs que chegava ao fim. O primeiro tocador bem-sucedido de MP3 começou a ser comercializado e anunciou uma nova relação dos consumidores com a música.

Com toda revolução apresentada, a empresa resolveu inovar novamente dando início a produção de candies, uma vez que até este momento a empresa concentrava suas atividades na produção de pó para 
refresco, pois o mercado de candies estava em franco desenvolvimento. O fato fica marcado na história como a bela Gisele Bündchen considerada, pela primeira vez, a modelo número 1 do mundo.

Para coroar este momento, a empresa consegue certificação ISO 9001, sendo um importante passo no seu processo de expansão enquanto o mundo comemora um dos maiores feitos da história da ciência: o mapeamento total do DNA humano.

No início da década de 2000, a empresa encontrou-se em um momento de franca expansão, era o momento de implantar uma nova linha de produção, e de aprimorar os conhecimentos de sua equipe comercial, dessa forma foi realizada a $1{ }^{\text {a }}$ Convenção Nacional de Vendas, em contrapartida a todo esse sucesso os Estados Unidos sofrem um grave atentado terrorista que destrói as torres gêmeas em Nova Iorque lançando uma nova visão sobre a globalização. O povo brasileiro comemora juntamente com Gustavo Kuerten o tricampeonato do torneio Roland Garros.

Para ficar lembrado na história, a empresa atinge pela primeira vez faturamento mensal superior a 1 milhão de reais e o Brasil comemora a conquista do pentacampeonato mundial na Copa do Mundo no Japão. O time de Felipão vence a Alemanha por 2 X 0.

Passada a euforia do Pentacampeonato Mundial, diversos analistas políticos iniciaram uma análise em que se desenvolveu a eleição de 2002, onde o Brasil vinha de duas eleições decididas em primeiro turno a favor de Fernando Henrique Cardoso (PSDB). Em parte, devido ao extenso período no poder, a popularidade de seu governo foi corroída no segundo mandato, quando ocorreram, em 1999, a crise cambial, com a consequente desvalorização do Real e, em 2001, o racionamento de energia, criando um cenário difícil para o candidato tucano José Serra na disputa eleitoral (Figueiredo \& Coutinho, 2003).

De acordo com o Instituto Datafolha, em outubro de 2002 a avaliação positiva (respostas “ótimo/ bom") do governo FHC era de 23\%, bem inferior à obtida em setembro de 1998, de 43\%, pouco antes de sua reeleição (Figueiredo \& Coutinho, 2003). A esse respeito, vale mencionar que, após três tentativas frustradas, o PT lançou Lula mais uma vez à presidência. Assim como nas eleições anteriores, seu nome não sofreu muita resistência dentro do PT. Lula venceu o senador Eduardo Suplicy, por uma vantagem de 84,4\% nas prévias do partido. Entretanto, esta foi a primeira vez que Lula precisou disputar prévias para sair candidato pela legenda.

Para melhor entendimento, numa conjuntura de desconfiança e incerteza para investimentos, muitos investidores temiam as medidas a serem tomadas por um candidato de esquerda, caso este viesse a ganhar a eleição. De fato, aconteceu de Lula (PT) ascender nas pesquisas de intenção de voto e o chamado risco Brasil, índice que mede a confiança dos investidores no país, subir. Foi adotado então por alguns economistas e comentarista políticos o termo "risco Lula" indicando que se este candidato viesse a ganhar a eleição, a economia do país poderia falir. Lula viu-se obrigado a assinar um texto, que ficou conhecido como Carta aos Brasileiros, prometendo que, caso ganhasse a disputa, não tomaria medidas que representassem grandes mudanças na política econômica brasileira, o que decepcionou setores da esquerda brasileira.

Mesmo obrigado assinar um texto, e, decepcionando setores da esquerda brasileira o metalúrgico Luiz Inácio Lula da Silva, foi eleito presidente do Brasil com 61,3\% dos votos válidos, contra 38,7\% de José Serra. Fundador do PT, Lula foi o primeiro candidato de esquerda a vencer uma eleição presidencial no país. Desta forma, passado mais uma eleição presidencial neste país, e que gerou muitas incertezas no mercado, Luis Inácio Lula da Silva toma posse como Presidente da República Federativa do Brasil, e, o mercado brasileiro de candies estagna como pode ser observado na figura 1. 


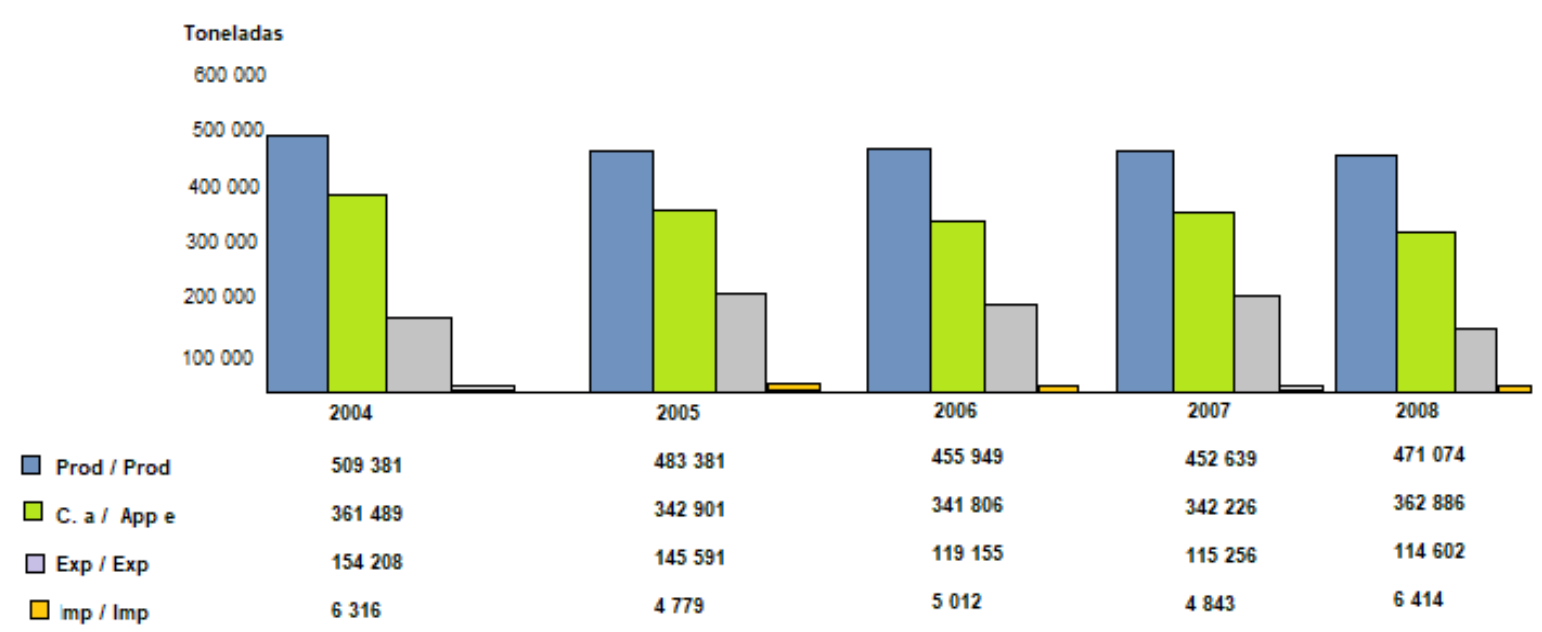

Fig. 1. Produção e exportação de balas, confeitos e gomas de mascar 2004/2008.

Fonte: Abicab (2015).

Segundo (Abicab, 2015), a produção brasileira de candies representou aproximadamente em 500 mil toneladas ano, e conforme podemos observar na figura 1, o consumo estava estabilizado próximo a 370 mil toneladas ano, no período de 2004 a 2008. Diante do exposto, mesmo com o mercado estabilizado, a busca do consumidor por produtos de maior valor agregado é bem perceptível no mercado de candies. Com o aumento da procura por produtos saudáveis e o envelhecimento da população brasileira, as empresas que produzem gomas de mascar, balas e confeitos precisam ofertar diferenciais além do simples prazer em degustar uma guloseima.

Nesse sentido, após a ampliação do parque fabril que aumentou em muito a capacidade de produção, e o lançamento de novas linhas de produtos, a demanda do mercado interno se estabiliza. E o que fazer agora?

Embora a acomodação do setor brasileiro de balas e candies em geral tenha sido superada desde meados da década passada, o declínio na demanda vem se acentuando nos últimos anos e o cenário ao longo dos anos 2000 mostra as indústrias do segmento conseguindo superar gargalos nas vendas domésticas, com investimento na modernização do parque industrial e apostas em linhas de maior valor agregado.

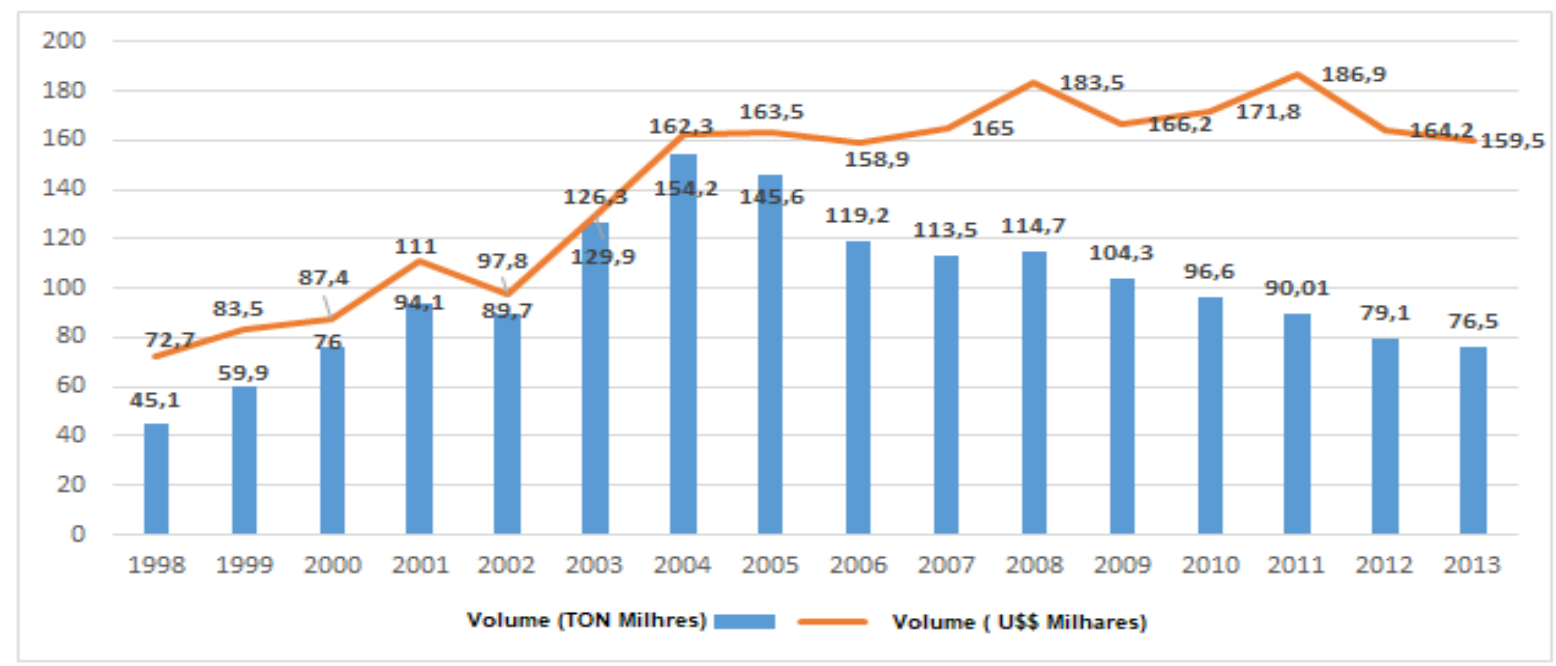

Fig. 2. Exportação de candies em volume e preço no período de 1983 a 2013.

Fonte: MDIC/ALCEWEB. Elaboração: IC-ABICAB (2015). 
A figura 2 demonstra que, embora se observe uma queda nos volumes de exportação verificados nos últimos anos, a receita continua estável o que permite desprender um aumento do valor unitário do produto, o que foi possível pelo lançamento de novas linhas de produto com maior valor agregado. Nessse novo modelo, o consumidor primeiro decide a categoria: gomas ou balas. Depois disso, vem à decisão da marca, sabor e formato da embalagem. Ter a gôndola organizada facilita esse processo e, assim, ajuda a incrementar as vendas (Abicab, 2015).

Já figura 3, demonstra a evolução da produção de 369 mil ton/ano para 443 mil ton/ano e que a queda na exportação, em volume, é compensada pelo aumento do volume de consumo aparente interno. Apesar dos desafios, trata-se de um segmento extremamente forte. O Brasil é o quinto maior mercado em valor de candies no mundo. O país é o terceiro colocado em volume de produtos de saúde e bem-estar na categoria de confeitos de açúcar e ocupa a $6^{\text {a }}$ posição na categoria de gomas de mascar, com 49,7 mil e 23,8 toneladas, respectivamente conforme (Abicab, 2015).

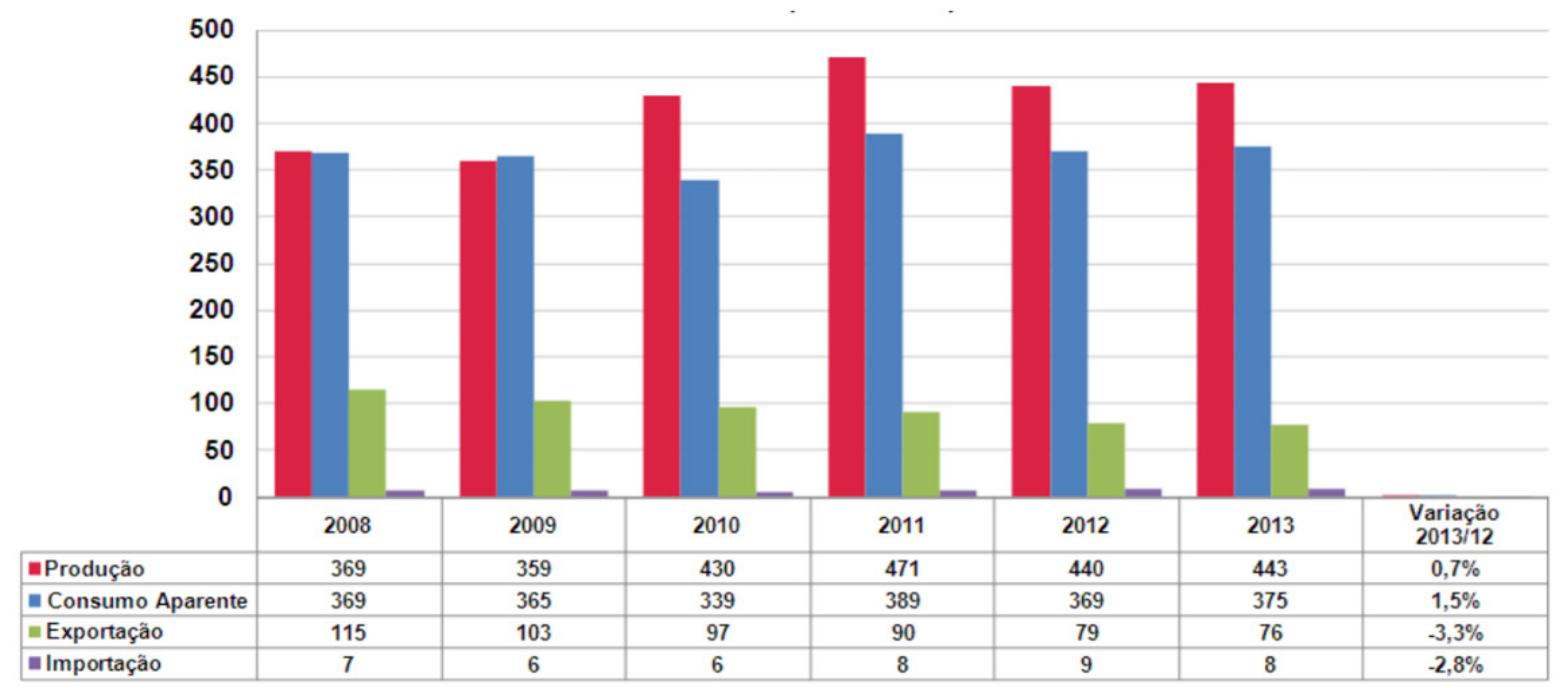

Figura 3: Produção, exportação e consumo aparente de balas, confeitos e gomas de mascar no período de 2008 a 2013.

Fonte: UHY MOREIRA - Auditores - Elaborado pelo setor de economia e estatística ABICAB-SICAB (2015).

Da mesma forma, o novo perfil de compra do consumidor direciona o mercado para a entrega de produtos não apenas com menos açúcar, mas que acrescente benefícios funcionais e ingrediente nutracêuticos, por exemplo. No Brasil e no exterior, várias empresas estão apostando em soluções criativas, e colhendo os resultados (Abicab, 2015).

\section{Estratégias de internacionalização e atuação}

A empresa sempre entendeu que se internacionalizar seria o caminho para o crescimento do negócio. Exportar possui diversos benefícios além da venda, tais como: utilização da capacidade ociosa das linhas de produção; serve como um hedge para diminuir os impactos nos custos de importações; traz novidades do mercado internacional que podem ser usadas no mercado doméstico.

Ao longo de sua história, a empresa já exportou para mais de 50 países. Atualmente, a mesma tem em sua carteira aproximadamente 43 países que nos últimos 24 meses adquiriram seus produtos, bem como comprando com certa regularidade. Nos dias atuais, a estratégia de internacionalização está focada nas Américas, até porque $80 \%$ do negócio de exportação está em todo o Continente Americano. 
Como política de mercado, a empresa participa das principais feiras nacionais e internacionais de negócio do segmento de doces, com objetivo de abertura de frentes de comercialização e intensificação de parcerias, como ISM (Alemanha) que é maior feira de doces do mundo, GULFOOD (Dubai), SWEETS \& SNACKS (Estados Unidos), ANUGA (Alemanha), SIAL (França), CONFITEXPO (México), APAS (São Paulo), ABAD (Curitiba), AGAS (Porto Alegre), EXPOVALE (Lajeado). A estratégia da empresa é focar no mercado latino americano, que é o mercado que tem uma cultura mais próxima da brasileira.

Por meio dessas feiras, a empresa conhece o público-alvo de cada país, e convivendo com tanta diversidade impulsiona a descoberta de novos sabores e a aposta em ideias vindas de outros países. Por exemplo: na África do Sul, surgiu à ideia de produzir balas de goma com aroma de iogurte e as minhocas azedinhas. Já na Europa, surgiu a necessidade de utilizar matérias-primas naturais na fabricação e nasceram as gomas de polpa de frutas, como as de goiabada e bananada.

Desta forma, as empresas usam diferentes estratégias para procurar seus primeiros clientes em novos mercados estrangeiros. Estes incluem feiras, propagandas e diferentes tipos de redes (Kontinen \& Ojala, 2011; Seringhaus \& Botschen, 1991). Na China, o uso de laços sociais como recurso está relacionado com a antiga tradição de confiar em redes interpessoais, baseadas em confiança ou "guanxi” (Ma, Yao \& Xi, 2009; Park \& Luo, 2001; Xin \& Pearce, 1996). Zhou et al. (2007, pág. 676) argumentam que as empresas usam redes sociais informais "[...] como uma estratégia preventiva para acessar informações e implantar os recursos relevantes de forma oportuna e flexível". Numerosos estudos ilustram que, na China, o uso do guanxi pelas empresas chinesas e estrangeiras é generalizado (Luk et al., 2008; Peng \& Luo, 2000; Standifird \& Marshall, 2000; Zhou et al., 2007). Ainda há muitas áreas em que outras evidências empíricas são necessárias para promover o desenvolvimento de redes e seus efeitos, por exemplo, se o uso de redes tem um efeito positivo no desempenho (Ellis, 2011; Harris \& Wheeler, 2005; Kontinen \& Ojala, 2011; Luo \& Hassan, 2009).

Para melhor entendimento, a evidência empírica corrobora a teoria, mostrando que as empresas baseadas em economias desenvolvidas e emergentes frequentemente dependem de redes de diferentes tipos para buscar, descobrir e explorar oportunidades de negócios em mercados estrangeiros, bem como buscar outros objetivos de nível firme (Agndal et al 2008, Chandra et al., 2009; Ciravegna, 2014; Jacks, 2008; Khanna \& Palepu, 2010; Kontinen \& Ojala, 2011; Mort \& Weerawardena, 2006; Musteen, Francis, \& Datta, 2010; Nadvi, 1999).

A partir disso, a missão da empresa, mais do que simplesmente agregar novidades ao portfólio, é agregar diferença ao mercado. Desta forma, como as exigências são mais altas nos mercados estrangeiros, a empresa é obrigada a elevar a qualidade dos produtos e esse ganho é percebido por todos.

Diante o exposto, nos países onde os clientes têm gostos ou desejos muito diferentes, é necessária uma estratégia de adaptação. Isso é consistente com o trabalho de Özsomer et al. (1991) cujo estudo encontrou uma relação positiva entre a padronização em programas de marketing. Resultados semelhantes também foram encontrados em um estudo realizado por Chhabra (1996) de empresas americanas na América do Sul. Por exemplo, reconheceu-se que as estratégias de promoção das exportações devem estar de acordo com os gostos, desejos, valores e atitudes no mercado externo (Smith \& Albaum, 2005). As características e disponibilidade de mídia também dependem do ambiente econômico do país. Assim, quanto maiores as diferenças entre os países, mais difícil é para a empresa adotar com sucesso uma estratégia de padronização.

Da mesma forma, o grau de adaptação da distribuição também depende das características do mercado externo, como o nível de desenvolvimento econômico ou os hábitos de compra específicos da cultura. Além disso, o desenvolvimento econômico no mercado externo também pode afetar o grau de adaptação dos preços 
devido ao seu impacto nos preços que os consumidores estão dispostos a pagar por certos produtos (Theodosiou \& Katsikeas 2001).

\subsection{Desafios para o futuro}

O desafio da empresa é aumentar o percentual de vendas nos mercados já atendidos, e expansão para novos mercados, dentre essa expansão, o mercado que mais desperta interesse pelo seu potencial de compra é americano. Nesse sentido empresa desenvolveu uma estratégia para atingir esse objetivo, primeiro passo foi à contratação de um profissional para trabalhar na área comercial, que resida nos Estados Unidos.

A escolha do mercado americano, como alvo principal de expansão de mercado, se deu pelos Estados Unidos ser o principal destino das exportações brasileiras, com participação de $24 \%$ (US \$ 38,4 milhões) e alta de $8 \%$ sobre o ano anterior. O mercado americano é atraente por ser o maior mercado consumidor mundial de candies especialmente para produtos com maior valor agregado.

Além de conseguir uma penetração no mercado americano outro desafio futuro é ter uma maior participação na comercialização de candies para a América Latina, que tem sido o segundo maior destino das exportações de candies produzidos no Brasil tendo como destino principal a Argentina. Exportar para a América Latina é importante pela proximidade logística e também pela proximidade psíquica oportunizando maior facilidade de acompanhamento e entendimento do mercado consumidor.

O terceiro grande desafio é aumentar o share de mercado no Brasil (mercado interno) que está entre os maiores mercados consumidores mundiais. Este processo teve início com a construção de uma segunda unidade elevando a capacidade produtiva para 2 milhões de quilos/mês.

Recentemente a empresa manifestou a intenção de instalar uma terceira unidade fabril, agora no Sudeste, para ficar mais próximo do maior mercado consumidor regional recaindo a escolha da instalação no estado de Minas Gerais, restando definir o município que receberá a fábrica. Ofertaram incentivos, para atrair a empresa, os municípios de Poços de Caldas e Pouso Alegre.

O processo de internacionalização serviu de alavanca para desenvolver o mercado interno, pois ao exportar para mercados mais exigentes, impinge à empresa padrões de qualidade e de produto elevados o que melhora significativamente a percepção da imagem da empresa no país.

\section{Fonte de dados}

A coleta de dados para a construção do presente caso de ensino ocorreu por meio de entrevista não estruturada com o responsável pelo setor de exportação da empresa, bem como foi realizada uma revisão bibliográfica para dar embasamento nos dados, que suportam as questões para a discussão em sala de aula.

\subsection{Questões para discussões}

1. Qual a principal motivação que levou a empresa a apostar na sua internacionalização?

2. Quais critérios adotados para a escolha dos países que a empresa passou atuar?

3. Qual o modelo de negócio escolhido para a sua internacionalização? Por que a escolha desse modelo? 


\section{Notas de ensino}

\subsection{Sinopse}

O presente caso de ensino trata de uma empresa do ramo alimentício do Vale do Taquari/RS, a Docile Alimentos, abordando o processo de internacionalização da empresa. Analisa o desempenho do mercado interno que em determinado momento apresenta-se estagnado, fazendo com que a empresa buscasse alternativas de utilização completa do parque fabril estabelecido. Nesse sentido a questão que motivou o desenvolvimento deste trabalho pode ser resumida na pergunta: quais as características que a empresa adotou em seu processo de internacionalização e quais mudanças foram empreendidas no momento atual em que a empresa estava vivendo? Diante o exposto, utilizou-se a teoria de Network como base para o processo de internacionalização da empresa.

\subsection{Público a que se destina}

O caso de ensino pode ser utilizado em cursos de graduação e pós-graduação - lacto e stricto sensu-que tenha como foco, temas relativos a negócios internacionais e, em particular, internacionalização de empresas de candies. Pode ser utilizada, também em instituições públicas e privadas de apoio a internacionalização, em workshops de discussões sobre as dificuldades e soluções encontradas pela a empresa em seu processo de internacionalização.

\subsection{Análise do caso}

Para facilitar a análise do caso, na tabela 1 é apresentada a ordem cronológica da evolução da empresa e de seu processo de internacionalização.

\section{Tabela 1}

Linha do tempo da história da Docile.

\begin{tabular}{c|l}
\hline $\mathbf{A n o}$ & \multicolumn{1}{c}{ Evento } \\
\hline $\mathbf{1 9 9 1}$ & Nasce a Glucoamido \\
\hline $\mathbf{1 9 9 4}$ & $\begin{array}{l}\text { A Glucoamido altera o foco de distribuidora e inicia a fabricação de refrescos em pó com a marca Suk } \\
\text { \& Uky }\end{array}$ \\
\hline $\mathbf{1 9 9 8}$ & $\begin{array}{l}\text { Para se tornar uma empresa alinhada com o mercado consumidor a Glucoamido altera o nome para } \\
\text { Docile }\end{array}$ \\
\hline $\mathbf{2 0 9 9}$ & A Docile inicia a produção de bala de goma, um dos seus produtos de maior reconhecimento \\
\hline $\mathbf{2 0 0 1}$ & A Docile conquista a certificação ISO 9001 \\
\hline $\mathbf{2 0 0 2}$ & $\begin{array}{l}\text { Ano de muita comemoração: a Docile atinge pela primeira vez um faturamento mensal superior a R\$ } \\
\text { 1 milhão. }\end{array}$ \\
\hline $\mathbf{2 0 0 5}$ & $\begin{array}{l}\text { Começa a produção da Mini Minty, a linha de pastilhas drageadas da Docile. A Docile é a única } \\
\text { empresa brasileira a produzir este produto. }\end{array}$ \\
\hline Dentro de preceitos sustentáveis, a Docile constrói a maior e mais importante fábrica do parque \\
\hline
\end{tabular}




\begin{tabular}{c|l}
\hline $\mathbf{2 0 0 8}$ & $\begin{array}{l}\text { A Docile passa a licenciar a marca Disney, estampando nas embalagens de seus produtos as carismáticas } \\
\text { e consagradas figuras de Mickey e seus amigos e da galera do High School Musical 3. }\end{array}$ \\
\hline $\mathbf{2 0 0 9}$ & $\begin{array}{l}\text { Com importante investimento em modernos equipamentos, inicia a produção dos chicles de bola } \\
\text { recheados Zoah! }\end{array}$ \\
\hline $\mathbf{2 0 1 1}$ & $\begin{array}{l}\text { Começam as operações da unidade nordeste da Docile - a fábrica em Jaboatão dos Guararapes - região } \\
\text { metropolitana de Recife, Pernambuco. }\end{array}$ \\
\hline $\mathbf{2 0 1 3}$ & $\begin{array}{l}\text { A empresa escreveu um novo capítulo em sua história com a inauguração da sua sexta linha de produtos, } \\
\text { o marshmallow. }\end{array}$ \\
\hline
\end{tabular}

Fonte: Elaborado pelos autores, com base nas informações da empresa.

Tabela 2

O processo de internacionalização da Docile

\begin{tabular}{c|l}
\hline Ano & \multicolumn{1}{c}{ Evento } \\
\hline $\mathbf{1 9 9 8}$ & No final desse período iniciou a exportação \\
\hline $\mathbf{2 0 0 4}$ & $\begin{array}{l}\text { A Docile abre fronteiras e se apresenta ao mercado internacional, a partir da participação em } \\
\text { importantes feiras de alimentos e candies. }\end{array}$ \\
\hline
\end{tabular}

Fonte: Elaborado pelos autores, com base nas informações da empresa.

\section{P1: Qual a principal motivação que levou a empresa a apostar na sua internacionalização?}

A internacionalização da empresa está diretamente ligada, ao fenômeno da globalização, abertura de novos mercados, visto que mercado nacional estava chegando a um nível de estagnação. Naquele momento a globalização era entendida como um fenômeno que podia aproximar mercados, economias e culturas resultantes do desenvolvimento tecnológico em algumas áreas que possibilitavam o fluxo de capital através de mercados nacionais. Dentro dessa nova realidade a internacionalização da empresa se apresentou como uma oportunidade de crescimento em um mercado até aquele presente momento desconhecido.

A empresa considerava o processo de internacionalização, como uma oportunidade de expandir seu negócio de forma gradual, aumentando seu envolvimento internacional, através do desenvolvimento de conhecimento sobre mercados e operações com um menor comprometimento de recursos possíveis. Outro fator importante que foi considerado é que mercado externo exige que seu produto tenha um nível ótimo de qualidade, não apenas na concepção final do seu produto, como também nos processos, gestão de pessoas e práticas ambientais. Atendendo estas exigências o produto se torna mais competitivo tanto no mercado externo quanto interno. Assim visando reduzir efeito do desconhecimento de mercado, a empresa começaria a internacionalização através de exportações para países vizinhos, ou relativamente semelhantes em termos de negócio.

A empresa utilizou como base para iniciar sua internacionalização a teoria de Networks, considerando que os próprios mercados devem ser encarados como redes de empresas (Johanson \& Mattson, 2012). Quando associada à internacionalização, dela decorre que a empresa vai desenvolver posições em redes no exterior. Embora sua premissa comportamental seja a mesma do modelo de Uppsala (Johanson \& Vahlne, 1992), as decisões acerca do processo de internacionalização serão determinadas direta ou indiretamente pelas relações no interior das redes de negócios. "Tanto o aprendizado quando o desenvolvimento da rede influencia e é influenciado pelo processo contínuo de internacionalização" (Welch \& Welch, 1996, p.14).

Com a exportação, o benchmarking é ampliado, sendo possível conhecer diversas novas tecnologias dentro de sua área de atuação nos diferentes mercados que estiver atuando. Também vai conseguir melhorar o 
networking nas diversas feiras e eventos internacionais do qual poderá participar.

Fazendo uso da teoria de Networks a empresa entende que as iniciativas internacionais seriam modos de seguir participantes da sua rede de negócios, ou ainda, modos de aperfeiçoar relacionamentos dentro da rede. Por esta visão, a empresa iria para o exterior inicialmente não como um movimento explícito de busca de mercado, mas sim para acompanhar suas conexões, sejam elas clientes, parceiros de negócios ou mesmo competidores; para responder a algumas pressões da rede como, por exemplo, instituições de financiamento ou agências governamentais; ou ainda para criar novas conexões no estrangeiro.

Outro fator que influencia na escolha da teoria de Networks é que a mesma defende a teoria que qualquer produto pode ser internacionalizado, desde que isto esteja alinhado com os interesses das relações já estabelecidas ou a serem desenvolvidas. Por outro lado, a perspectiva de Empreendedorismo Internacional não parece colocar quaisquer restrições ao que poderia ser internacionalizado, sendo esta escolha determinada pelo tomador de decisão, dessa forma a empresa não ficaria refém de um determinado produto.

\section{P2: Quais critérios adotados para a escolha dos países que a empresa passou atuar?}

Tendo como base a teoria de networks prevê que a escolha do país se dará de acordo com as redes internacionais estabelecidas ou almejadas. Esta dinâmica interna da rede de negócios permite um efeito de redução de risco percebido da internacionalização, resultando num comportamento similar ao da redução da distância psíquica. Já na visão de empreendedorismo, novamente esta escolha dependerá do perfil do tomador de decisão (Andersson, 2000). Se for "técnico", a escolha de mercados dependeria de quais países estivessem fazendo solicitações. Se for "estrutural", agiria em indústrias maduras, cuja maior parte já é global. E se for voltado para o marketing atuaria, em geral, em mercados novos ou em crescimento. Na escolha de mercados, preferências pessoais (advindas, por exemplo, de experiências prévias) e redes de contatos pessoais podem ser mais importantes do que cálculos "racionais".

Dentro dos critérios estabelecidos para início de sua internacionalização, tendo como base o modelo networks a Docile teve como base os países das Américas, por estes estarem mais próximos de sua unidade fabril, facilitando a logística de entrega dos produtos e pelo fato da empresa conhecer um pouco da cultura desses países, pois proximidade territorial facilita esse conhecimento. Também devemos considerar que os produtos que serão exportados podem necessitar de uma adaptação para o mercado o qual será inserido. As diferenças culturais podem ser gigantescas entre os países, e esta prática de adequação pode gerar custos extras no início do processo, dessa forma quanto mais perto for o país escolhido para exportação, menores serão os custos de adaptação.

Outro fator que pesa nessa escolha é que a empresa vai poder definir a estratégia a ser adotada, na rede em que ela atua, de acordo com grau de internacionalização do mercado que ela está atuando.

A premissa comportamental da abordagem de Networks é a mesma do modelo de Uppsala, mas a internacionalização depende tanto da própria empresa quanto do mercado (network). Assim, as empresas poderiam adotar comportamentos diferentes de acordo com o grau de internacionalização da empresa e de seu mercado. Se ambos forem baixos, a empresa seguiria o preconizado pelo Modelo de Uppsala. Um mercado muito internacionalizado "puxaria" via sua network as empresas. Caso, tanto a empresa quanto o mercado fossem internacionalizados, o foco estaria em integrar networks de diferentes origens (Johanson \& Mattson, 2012). 


\section{P3: Qual o modelo de negócio escolhido para a sua internacionalização? Por que a escolha desse modelo?}

A Docile escolheu como seu modelo de negócio para internacionalização a teoria de Network, sendo está escola considerada como uma importante linha de pensamento na vasta literatura existente sobre negócios internacionais.

Essa escolha se deu pela questão das redes de relacionamentos (networks) serem consideradas uma evolução natural do pensamento da Escola Nórdica. Seus seguidores têm desempenhado papel central no desenvolvimento da perspectiva das networks industriais, focalizando os relacionamentos existentes entre firmas e mercados industriais. Nesse sentido, Johanson e Mattsson (2015) afirmam que os fatores e as forças competitivas em indústrias altamente internacionalizadas, criam um padrão heterogêneo de oportunidades de entrada. Essa heterogeneidade motivará a firma a escolher mercados e estratégias de entrada, que poderão ser bem diferentes do que é previsto pelo modelo tradicional de Uppsala; porém isso somente será possível mediante o estabelecimento de redes de relacionamentos nos novos mercados a serem servidos. Assim os relacionamentos, tanto estritamente de negócios (Johanson e Vahlne, 2003) quanto pessoais (Lindqvist, 1991), podem ser usados como pontes para a entrada em outras networks.

Dessa forma podemos dizer que empresa optando por esse modelo de negócio tem uma maior autonomia, na hora de definir suas estratégias de atuações em mercados internacionais, que um fator preponderante a ser analisado será a escolha da rede de relacionamentos que mesma vai querer seguir, que estas escolhas terão papel fundamental em decisões futuras, servindo não somente para ampliar seu mercado de atuação, mas sim como uma forma cognitiva da exploração de culturas diferentes.

Johanson e Vahlne (1992) explicaram que as interações entre atores, mais do que o processo de decisão estratégica, dão forma às estruturas da network. Para Björkman e Forsgren (2000) a teoria das networks, em vez de se ater aos fatos econômicos para explicar a internacionalização da firma, se concentra nos laços cognitivos e sociais que se formam entre os atores que mantêm relacionamentos de negócios. Do ponto de vista das networks, o contexto de negócios baseia-se, em grande parte, em relacionamentos específicos com outros atores. Com essa teoria entende-se melhor quais são os fatores decisivos subjacentes ao processo de internacionalização da firma. Ao mesmo tempo, a teoria sugere que o grau de internacionalização de uma firma reflete não somente os recursos alocados no exterior, mas também o grau de internacionalização da network em que ela está inserida. Assim a internacionalização deixa de ser somente uma questão de mudar a produção para o exterior e passa a ser percebida mais como a exploração de relacionamentos potenciais além-fronteiras (Andersson \& Johanson, 1997).

\subsection{Utilização do case em aula dinâmica}

O professor inicia a aula falando sobre o processo de expansão de uma empresa partindo do nível regional para o estadual e nacional através da avaliação de cenários políticos e econômicos. Uma vez atingido esse patamar e desenvolvendo as qualificadoras a empresa está apta para buscar o mercado internacional. A partir disso se aborda as teorias da internacionalização abrangendo questões culturais, sociais e políticas. (20 minutos)

a) Após a explanação inicial, professor divide a turma em grupos e distribui o caso (documento 01) (10 minutos)

b) Discussão por parte dos grupos sobre resoluções do caso baseado nas teorias apresentadas (30 minutos) 
c) Discussão das soluções no grande grupo (30 minutos)

Tempo estimado $1 \mathrm{~h} 30 \mathrm{~min}$.

\section{Referências}

Agndal,H., \& Nilsson,U.(2008). Supply chain decision-making supported by an open books policy. International Journal of Production Economics, 116(1), 154-167.

Andersson, S. (2000). The internationalization of the firm from an entrepreneurial perspective. International studies of management \& organization, 30(1), 63-92.

Andersson, U., \& Johanson, J. (1997). International business enterprise.

Associação Brasileira da Indústria de Chocolates, Amedion e Balas. (2015). Acesso em: http://blog.indumak. com.br/mercado-de-candies/. Acesso em 20 agos.2018.

Björkman, I., \& Forsgren, M. (2000). Nordic international business research: a review of its development. International Studies of Management \& Organization, 30(1), 6-25.

Ciravegna, L., Lopez, L. e Kundu, S. (2014). País de origem e efeitos da rede na internacionalização: um estudo comparativo das PME de uma economia emergente e desenvolvida. Journal of Business Research, 67 (5), 916-923.

Chandra, Y., Styles, C., \& Wilkinson, I. (2009). O reconhecimento de oportunidades empreendedoras internacionais pela primeira vez: Evidências de empresas em indústrias baseadas no conhecimento. International Marketing Review, 26 (1), 30-61.

Chhabra, SS (1996). Adaptações de marketing por corporações multinacionais americanas na América do Sul. Jornal de Marketing Global, 9 (4), 57-74.

Ellis, P.D. (2011). Laços sociais e empreendedorismo internacional: Oportunidades e restrições que afetam a internacionalização das empresas. Jornal de estudos de negócios internacionais, 42 (1), 99-127.

Harris, S., \& Wheeler, C. (2005). Entrepreneurs' relationships for internationalization: functions, origins and strategies. International business review, 14(2), 187-207.

Jacks, D. S., Meissner, C. M., \& Novy, D. (2008). Trade Costs, 1870-2000. American Economic Review, 98(2), 529-34.

Johanson, J., \& Mattsson, L. G. (2015). Internationalisation in industrial systems - a network approach. In Knowledge, networks and power (pp. 111-132). Palgrave Macmillan, London. 
Johanson, J. (2012). International Marketing and Internationalization Processes-A Network Approach Jan Johanson and Lars Gunnar-Mattsson University of Uppsala and Stockholm School of Economics. Research in International Marketing (RLE International Business), 234.

Johanson, J., \& Vahlne, J. E. (2003). Business relationship learning and commitment in the internationalization process. Journal of international entrepreneurship, 1(1), 83-101.

Johanson, J., \& Vahlne, J. E. (1992). Management of foreign market entry. Scandinavian International Business Review, 1(3), 9-27.

Khanna, T., \& Palepu, K. (2010). Winning in the emerging economies: A road map for strategy and execution.

Kontinen, T., \& Ojala, A. (2011). Rede de laços no reconhecimento de oportunidades internacionais de PME familiares. International Business Review, 20 (4), 440-453.

Lindqvist, M. (1991). Infant multinationals. Stockholm: Stockholm school of economics. Inst. of intern business.

Luo, X., \& Hassan, M. (2009). O papel das redes de gestão de topo na criação e partilha de conhecimento de mercado na China. Jornal de pesquisa de negócios, 62 (10), 1020-1026.

Luk, C.L., Yau, O.H., Pecado, L.Y., Alan, C.B., Chow, R.P. \& Lee, J.S. (2008). Os efeitos do capital social e da inovação organizacional em diferentes contextos institucionais. Jornal de Estudos Internacionais de Negócios, 39 (4), 589-612.

Ma, X., Yao, X., \& Xi, Y. (2009). Como as redes interorganizacionais e interpessoais afetam a capacidade adaptativa estratégica de uma empresa em uma economia de transição?. Journal of Business Research, 62 (11), 1087-1095.

Musteen, M., Francis, J., \& Datta, D. K. (2010). The influence of international networks on internationalization speed and performance: A study of Czech SMEs. Journal of World Business, 45(3), 197-205.

Nadvi, K. (1999). Collective efficiency and collective failure: the response of the Sialkot surgical instrument cluster to global quality pressures. World development, 27(9), 1605-1626.

Ozsomer, A., Bodur, M., \& Tamer Cavusgil, S. (1991). Marketing standardisation by multinationals in an emerging market. European Journal of Marketing, 25(12), 50-64.

Park, S.H., \& Luo, Y. (2001). Guanxi e dinâmica organizacional: redes organizacionais em empresas chinesas. Revista de gestão estratégica, 22 (5), 455-477. 
Peng, M.W., \& Luo, Y. (2000). Laços gerenciais e desempenho da empresa em uma economia de transição: a natureza de um link micro-macro. Academia de revista de gestão, 43 (3), 486-501.

Seringhaus, F. R., \& Botschen, G. (1991). Cross-national comparison of export promotion services: the views of Canadian and Austrian companies. Journal of International Business Studies, 22(1), 115-133.

Smith, S. M., \& Albaum, G. S. (2005). Fundamentals of marketing research. Sage.

Standifird, S. S., \& Marshall, R. S. (2000). The transaction cost advantage of guanxi-based business practices. Journal of world business, 35(1), 21-42.

Theodosiou, M., \& Katsikeas, C. S. (2001). Factors influencing the degree of international pricing strategy standardization of multinational corporations. Journal of International Marketing, 9(3), 1-18.

Xin, K. K., \& Pearce, J. L. (1996). Guanxi: Connections as substitutes for formal institutional support. Academy of management journal, 39(6), 1641-1658.

Welch, D. E., \& Welch, L. S. (1996). The internationalization process and networks: a strategic management perspective. Journal of international marketing, 11-28.

Weerawardena, J., \& Mort, GS (2006). Investigando o empreendedorismo social: um modelo multidimensional. Jornal dos negócios mundiais, 41 (1), 21-35.

Zhou, T., Ren, J., Medo, M., e Zhang, YC (2007). Projeção de rede bipartida e recomendação pessoal. Physical Review E, 76 (4), 046115. 